\title{
Incretin-Based Therapy and Risk of Pancreatic Cancer in Patients with Type 2 Diabetes Mellitus: A Meta-analysis of Randomized Controlled Trials
}

\author{
Han Chen · Xiaoying Zhou · Tao Chen · Bingtuan Liu • \\ Wujuan Jin · Huiyuan Gu · Tianyuan Hong · Guoxin Zhang
}

Received: July 30, 2016/Published online: September 21, 2016

(C) The Author(s) 2016. This article is published with open access at Springerlink.com

\begin{abstract}
Introduction: The present study aims to evaluate the risk of pancreatic cancer with incretin-based therapy among patients with type 2 diabetes mellitus (T2DM).
\end{abstract}

Enhanced content To view enhanced content for this article go to http://www.medengine.com/Redeem/ 2FD6F0603A66AFFE.

Electronic supplementary material The online version of this article (doi:10.1007/s13300-016-0198-3) contains supplementary material, which is available to authorized users.

H. Chen · X. Zhou · T. Chen · B. Liu · T. Hong ·

G. Zhang ( $\square)$

Department of Gastroenterology, The First Affiliated

Hospital of Nanjing Medical University,

Nanjing 210029, China

e-mail: guoxinz@njmu.edu.cn

H. Chen · X. Zhou · T. Chen · B. Liu - T. Hong •

G. Zhang

First Clinical Medical College of Nanjing Medical

University, Nanjing 210029, China

W. Jin

Department of Gastroenterology, Sir Yifu Hospital Affiliated with Nanjing Medical University,

Nanjing 210029, China

H. Gu

Department of Gastroenterology, The First Affiliated Hospital of Soochow University, Suzhou 215006, China
Methods: We searched EMBASE, MEDLINE, the Cochrane Central Register of Controlled Trials and ClinicalTrials.gov for eligible studies published up to March 06 2016. This meta-analysis includes all studies reporting adverse events of pancreatic cancer with use of incretin-based therapies compared with placebo or non-incretin anti-diabetic drugs in patients with T2DM. We used fixed-effect model to compare pooled relative risk (RR) with related 95\% confidence intervals (CI).

Results: A total of 159 randomized trials were identified. Out of these, 135 studies were excluded as pancreatic cancer occurrence had not been included as an end point. The remaining 24 trials enrolling 47,904 participants were further assessed. Overall, no increased risk of pancreatic cancer were detected in association with incretin-based treatment $(\mathrm{RR}=0.7,95 \% \mathrm{CI} 0.37-1.05)$. The incidence of pancreatic neoplasm was even lower among incretin-based groups than controls $\quad(\mathrm{RR}=0.50, \quad 95 \% \quad \mathrm{CI} \quad 0.29-0.87)$ in trials with duration more than 104 weeks. There was even decreased risk of pancreatic cancer within groups paralleled by incretin-matched placebos $(\mathrm{RR}=0.55,95 \% \mathrm{CI}$ 
0.32-0.93) than by non-incretin anti-diabetic drugs. Neither monotherapy $(\mathrm{RR}=0.62,95 \% \mathrm{CI}$ 0.38-1.01) nor combination regimen $(\mathrm{RR}=0.92, \quad 95 \% \quad \mathrm{CI} \quad 0.45-1.90)$ of incretin mimetics increased the risk of pancreatic cancer.

Conclusion: This meta-analysis shows that incretin-based therapies are not associated with increase in the risk of pancreatic cancer. Interestingly, subgroup analyses suggested lower risk of pancreatic cancer in incretin groups than placebo in long-term studies (>104 weeks). Considering the inconsistent results among randomized trials and previous epidemiological investigations, more such studies should be conducted to clarify the existence or non-existence of this association.

Funding: This work was supported by grants from the National Natural Science Foundation of China (Nos. 81270476 and 81470830).

Keywords: Anti-diabetic drug; Incretin-based therapy; Pancreatic cancer; Type 2 diabetes; Meta-analysis

\section{INTRODUCTION}

Over the last decade, the worldwide prevalence of type 2 diabetes mellitus (T2DM) has increased the use of incretin-based drugs [1-3]. There are two types of incretin-based drugs, glucagon-like peptide-1 receptor agonists (GLP-1RAs) and dipeptidyl peptidase-IV (DPP-IV) inhibitors, both with pharmacological effects reflecting interactions between the gut and the endocrine system [4]. Currently, evidence from previous studies has illustrated the advantages of incretin-based therapies [4, 5]. GLP-1RAs (incretin mimetics) have been shown to effectively lower blood glucose and promote weight loss with minimal hypoglycemia [5]. Meanwhile, DDP-IV inhibitors (incretin enhancers) have intermediate efficacy on glucose control with weight neutral effect and low risk of hypoglycemia [5-7].

Although proponents claim that the pharmacological advantages of incretin drugs outweigh their potential risks, yet, there is insufficient evidence about their long-term adverse effects, especially on the exocrine pancreas. Over the recent past, safety cautions have been raised with regard to pancreatic safety of incretin-based therapies. In 2011, Elashoff et al. conducted a retrospective investigation from the US Food and Drug Administration (FDA) database, and concluded that the risk of pancreatic cancer was 2.9-fold greater with exenatide as compared with other anti-diabetic drugs [8]. Subsequently, the Drug Commission of German Medical Association reported similar concerns [9]. As these findings suggested that incretin mimetics increase the risk of development of pancreatic cancer, more studies began to focus on the pancreatic safety of incretin drugs.

In the last 5 years, various epidemiological observational and randomized controlled clinical trials (RCTs) have been conducted worldwide to establish this association. Nevertheless, the inconsistent findings among different studies have posed a dilemma of uncertainty about the association between incretin-based drugs and risk of pancreatic cancer. In 2014, Amy et al. reviewed the pancreatic safety of incretin-based therapies by evaluating FDA and European Medicines Agency (EMA) database. Although their conclusions seem to provide a definitive statement that the available scientific evidence does not support a causal association between incretin-based drugs and pancreatic cancer [10], there is no current pooled data providing direct 
evidence from the standpoint of evidence-based medicine to support such a conclusion. Actually, much of the controversy was generated by Peter Butler and colleagues initially, when they speculated this association from the results of animal study involving genetically modified rats in year 2009; followed by an adverse experience database study in 2011 and finally by an analysis of post-mortem samples in 2013 [11-13]. Therefore, in order to provide more compelling evidence, we conducted a meta-analysis by investigating all RCTs regarding any information about pancreatic cancer events during incretin-based treatments.

\section{METHODS}

\section{Eligibility Criteria}

This meta-analysis, conducted in accordance with PRISMA guidelines, included all studies reporting adverse events of pancreatic cancer with use of incretin-based therapy GLP-1RAs and DPP-IV inhibitors compared with placebo or other non-incretin anti-diabetic drugs in patients with T2DM. Studies fulfilling the following criteria were included: (i) RCTs; (ii) studies must include an intervention group with T2DM patients treated by incretin-based therapy (studies enrolling healthy patients, on-diabetic cases, or patients with type 1 diabetes mellitus were excluded); (iii) patients with T2DM must have been studied for at least 24 weeks of treatment period (trials with shorter terms will not be able to demonstrate this association between incretin treatment and pancreatic cancer as it is thought to be a long-term adverse event); (iv) treatment for a minimum of 12 weeks with DPP-IV inhibitors in monotherapy or combination therapy or GLP-1 RA versus placebo or any anti-diabetic drug (oral hypoglycemic agent or insulin); (v) studies that yielded relevant information on reporting adverse events, regardless of whether the incidence of pancreatic cancer was the principal outcome variable or not.

\section{Information Sources and Search Strategy}

We searched databases of EMBASE, MEDLINE and the Cochrane Central Register of Controlled Trials (CENTRAL) for all the trials published up to March 06 2016. Both medical subject headings and free terms were used to identify relevant articles: 'GLP-1-mimetics', 'incretin mimetic drugs', 'incretin-based therapies', 'Glucose Dependent Insulin Releasing Hormone', 'incretin effects', 'Glucagon Like Peptide 1 receptor agonist', 'GLP-1 RAs', 'GLP-1-mimetics', 'GLP-1 agonists', 'albiglutide','exenatide','liraglutide', 'Dipeptidyl Peptidase IV Inhibitors', 'Dipeptidyl-Peptidase IV', 'DPP-4 inhibitor', 'alogliptin', 'saxagliptin', 'sitagliptin', 'linagliptin', 'vildagliptin', 'Pancreatic Neoplasm', 'Pancreatic Cancer', 'Cancer of the Pancreas'.

ClinicalTrials.gov was also searched as it is an important resource of RCTs. All registered clinical trials from phase II to phase IV of incretin-based therapies were screened in this study. Registered trials undergoing recruiting process; not completed or those without any reporting of adverse events were excluded. Meta-analyses previously published on investigating pancreatic safety associated with incretin drugs were also assessed for potential eligible studies.

\section{Data Collection Process}

Eligible studies were screened by two trained reviewers independently (HC and XYZ). The 
first reviewer (HC) obtained the eligible studies by screening titles and abstracts of publications. As for unpublished clinical trials, basic information of study design and adverse events were primarily checked. The second reviewer (XYZ) further screened these papers using the eligibility criteria. Reference lists of relevant publications were also screened for potentially eligible studies. Discrepancies were resolved by consensus between two reviewers. Data extraction process was finished by four other reviewers (BTL, WJJ, and HYG).

\section{Risk of Bias Across Studies}

Statistical heterogeneity across the studies was assessed visually with Begger's [31] funnel plot. Furthermore, Egger test and Harbord's modified test [32] were also applied in this study.

\section{Risk of Bias in Individual Studies}

The Cochrane tool [33] for RCTs was applied for bias assessment. The following domains were evaluated for study reliability: the adequacy of randomization and concealment of allocation, blinding of participants, personnel and outcome assessors, the extent of loss to follow-up, the assessment of selective outcome reporting, and other sources of bias.

\section{Statistical Analysis}

These meta-analyses were primarily conducted with STATA (version 14.0, StataCorp, College Station, TX, USA). Statistical heterogeneity were quantified by Chi-square-based $Q$ test and $I^{2}$ statistic (0-40\%: minor; 30-60\%: moderate; 50-90\%: substantial; 75-100\%: considerable) [34]. A fixed-effect model was used to compare pooled relative risk (RR) with related 95\% confidence intervals (CIs).

\section{Compliance with Ethics Guidelines}

This article is based on previously conducted studies and does not involve any new studies of human or animal subjects performed by any of the authors.

\section{RESULTS}

\section{Description of Studies}

The initial search identified a total of 5823 studies: 5549 from MEDLINE/EMBASE/ CENTRAL database and 274 from Clinicaltrial.gov. Of these, 4987 records were excluded due to irrelevant topics. 462 full-text articles and 274 clinical trials were assessed for eligibility. After excluding non-randomized and observational studies, studies with non-T2DM patients and studies with no interest of outcome, we identified 159 RCT (Fig. 1). Of these, 135 did not disclose their results or did not report any adverse events of pancreatic cancer (supplement table). The remaining 24 trials [14-30] enrolling 47,904 patients were included in this meta-analysis. The study characteristics are summarized in Table 1. A total of 24,462 patients had received incretin-based regimens while 23,434 had received placebo or other non-incretin-based treatments such as metformin or glimepiride.

\section{Risk of Bias Assessment}

The assessed quality of publication was of medium- to high-quality evidence and two studies (NCT01064687 and Jadzinsky 2009) $[14,25]$ had high risk of bias as these two studies had reported incomplete data (Fig. 2a, b). Begg's funnel plot $(P=0.309)$ suggests no evidence of heterogeneity (Fig. 3). However, Egger's test $(P=0.019)$ and Harbord's modified 


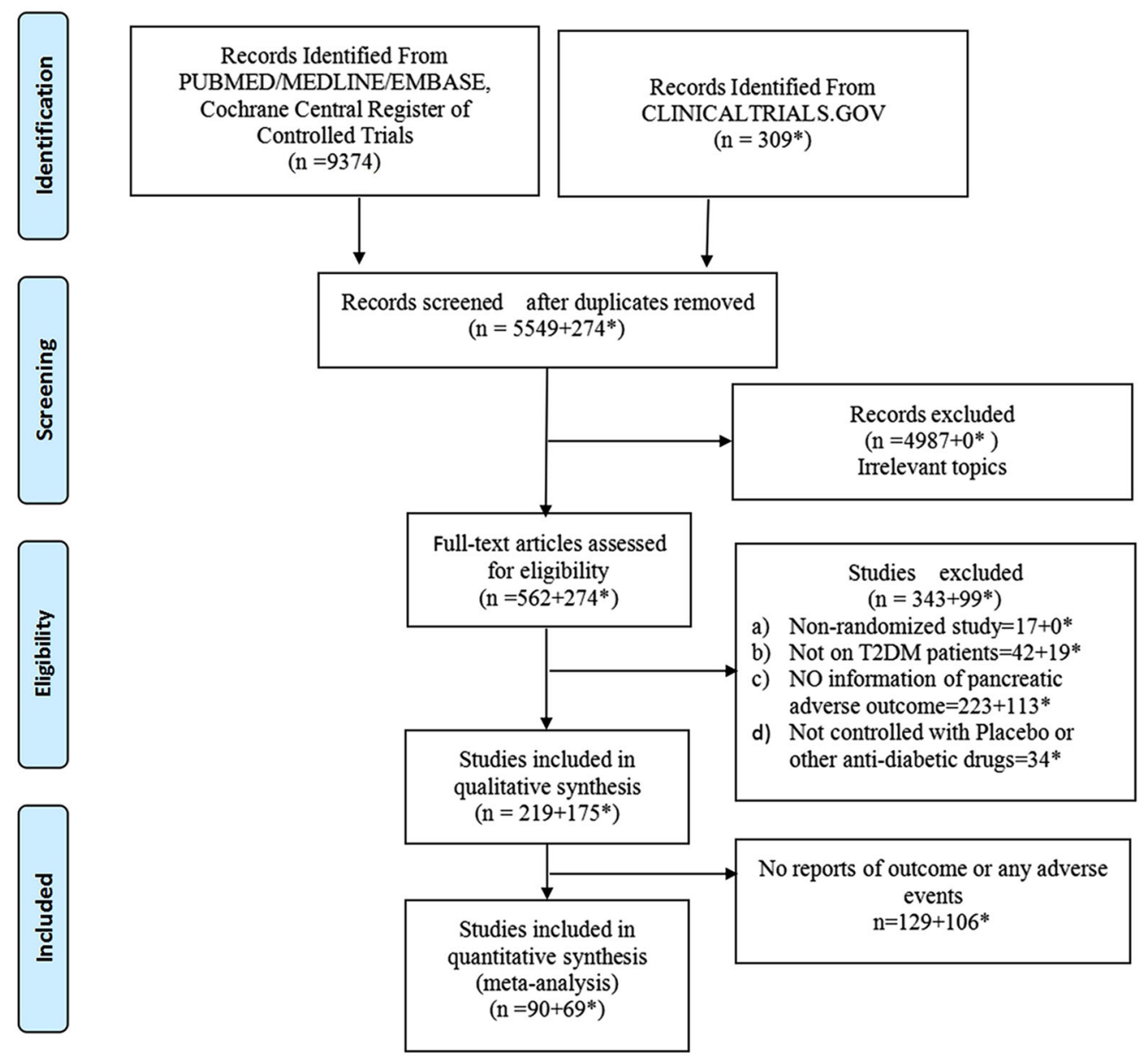

* Search From CLINICALTRIALS.GOV

Fig. 1 Flow chart. A total of 159 randomized controlled trials were identified. Of these, 135 did not disclose their results or did not report any adverse events of pancreatic

test $\quad(P=0.038) \quad$ indicates potential heterogeneity across the studies.

\section{Risk of Pancreatic Cancer}

Within all the assessed trials, $1.59 \%$ of patients developed pancreatic cancer after exposure of incretin drugs (1.3\% in those taking incretins; $1.9 \%$ in control patients). None of these studies mentioned specific diagnostic criteria of pancreatic cancer. Within all 24 trials, there was no increased risk of pancreatic neoplasm associated with incretin-based treatment cancer. The remaining 24 trials were finally assessed. $T 2 D M$ type 2 diabetes mellitus

(pooled $\quad \mathrm{RR}=0.7, \quad 95 \% \quad \mathrm{CI} \quad 0.47-1.05$, $P=0.083)$, irrespective of different types of incretin drugs (GLP-1RA: pooled $\mathrm{RR}=0.58$, 95\% CI $\quad 0.26-1.33, \quad P=0.198 ; \quad$ DPP-IV inhibitors: pooled $\mathrm{RR}=0.74, \quad 95 \% \quad \mathrm{CI}$ 0.46-1.18, $P=0.210$ ). Our findings were generally consistent in sensitivity analyses. The pooled results, however, contained potential heterogeneity among different studies. These heterogeneous factors include specific types of incretin-based drugs (GLP-1RAs or DPP-IV inhibitors), controlled drugs (placebo or other non-incretin drugs of 


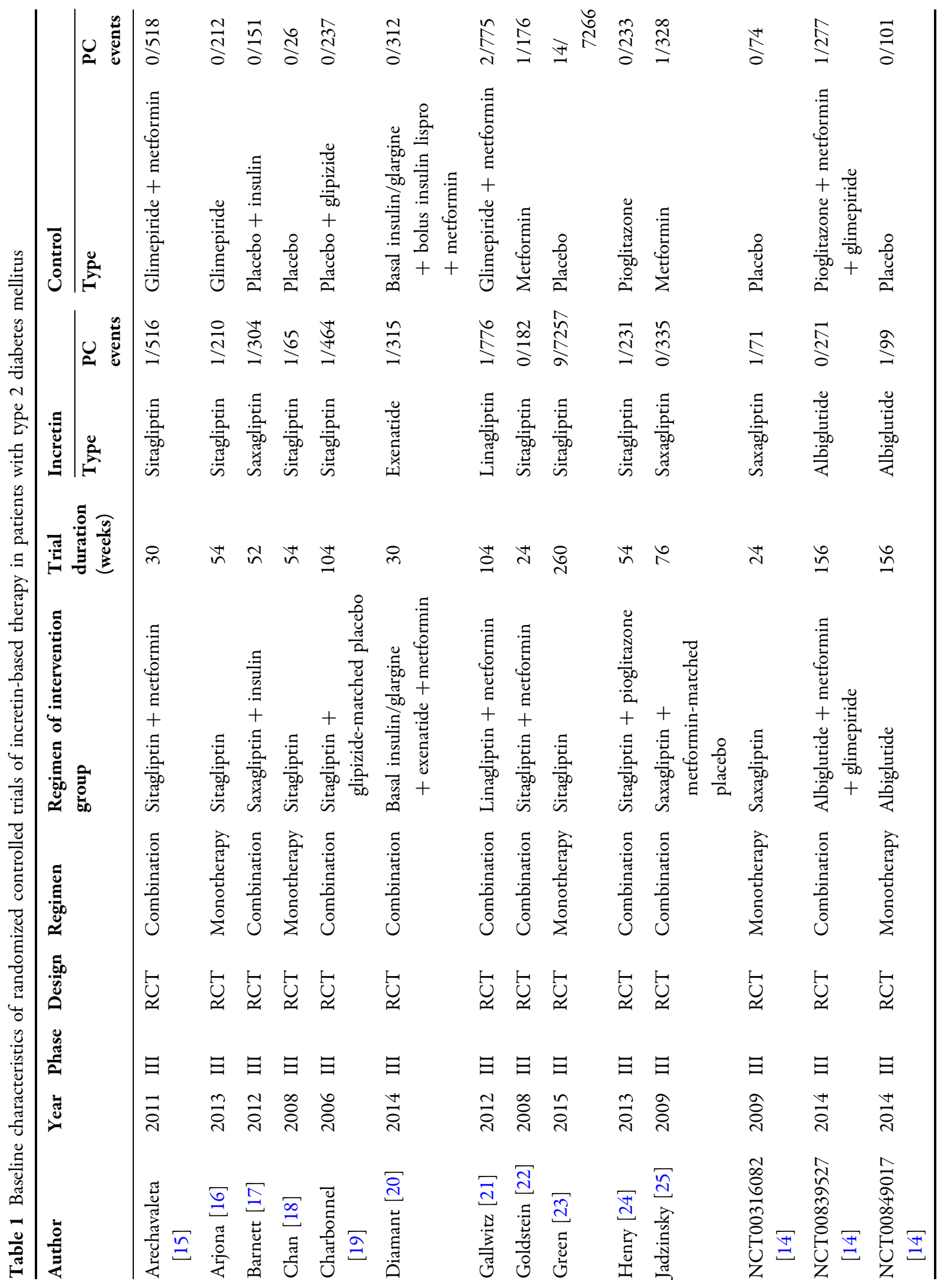


U

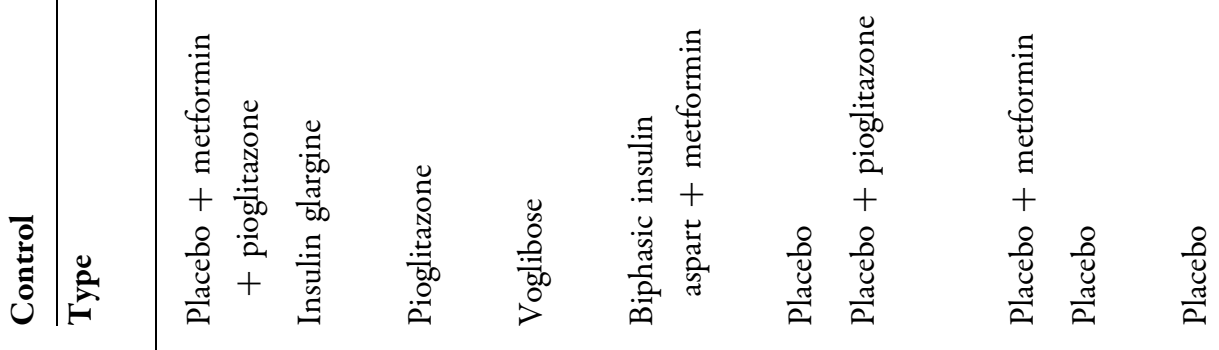

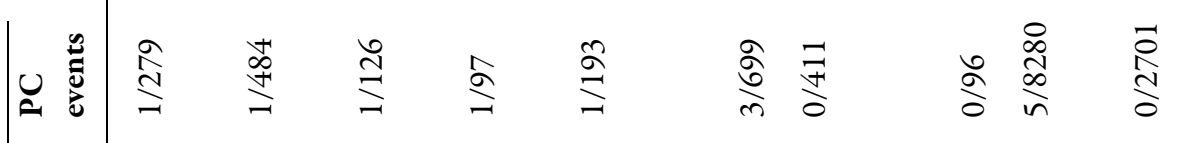

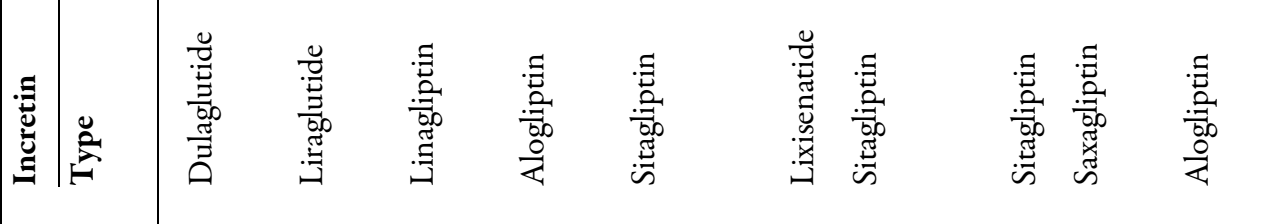

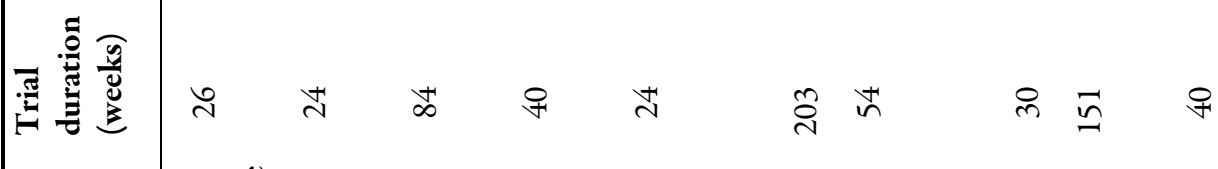

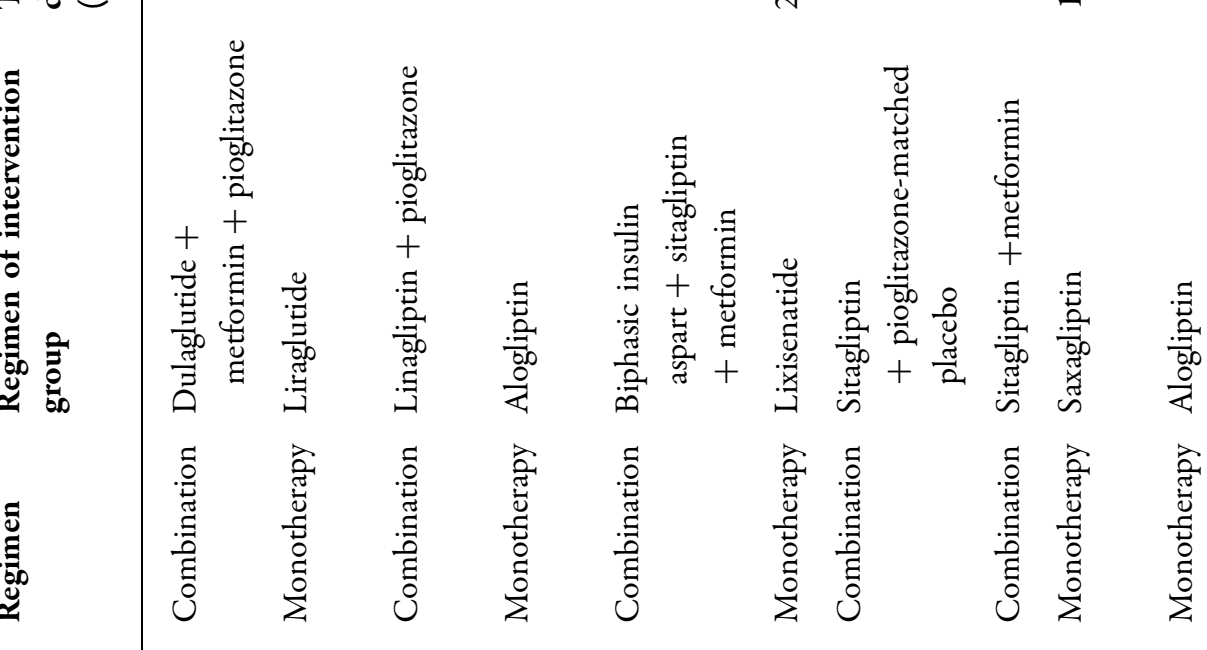

告

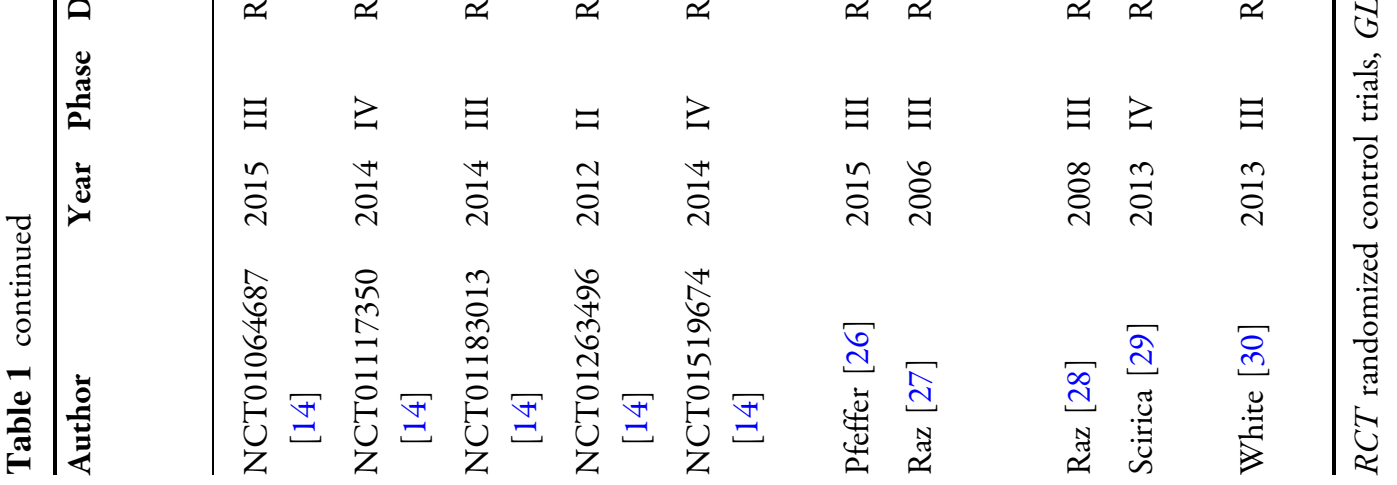




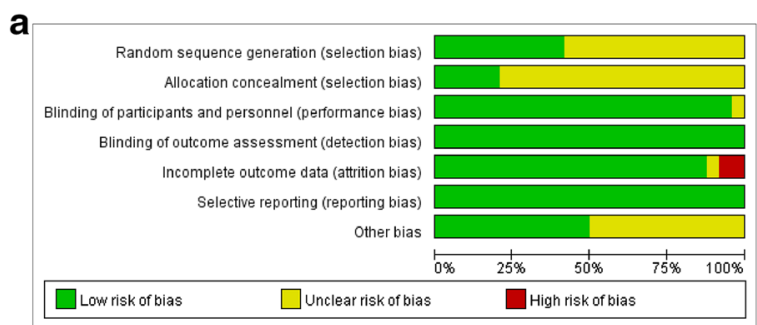

b

\begin{tabular}{|c|c|c|c|c|c|c|c|}
\hline & 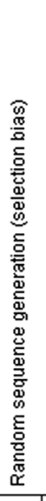 & 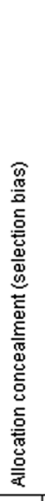 & 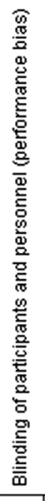 & 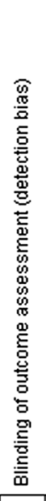 & 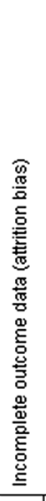 & 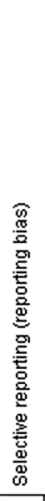 & 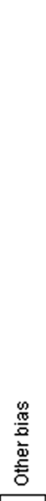 \\
\hline Arechavaleta 2011 & $\odot$ & $\odot$ & $\odot$ & + & $\odot$ & $\odot$ & + \\
\hline Arjona Ferreira 2013 & $\odot$ & $?$ & $\odot$ & + & $\odot$ & $\odot$ & + \\
\hline Barnett 2012 & $\odot$ & $\odot$ & $\odot$ & + & $\odot$ & $\odot$ & $\odot$ \\
\hline Chan 2008 & $?$ & $?$ & $\odot$ & + & $\odot$ & $\odot$ & + \\
\hline Charbonnel 2006 & $?$ & $?$ & $\odot$ & + & $\odot$ & $\odot$ & + \\
\hline Diamant 2014 & $\odot$ & $?$ & $?$ & + & $\odot$ & $\odot$ & + \\
\hline Gallwitz 2012 & + & $?$ & $\odot$ & + & $\odot$ & $\odot$ & $\odot$ \\
\hline Goldstein 2008 & $\odot$ & $?$ & $\odot$ & + & $\odot$ & + & + \\
\hline Green 2015 & $\odot$ & $\odot$ & $\odot$ & + & $\odot$ & (†) & + \\
\hline Henry 2013 & $\odot$ & $\odot$ & $\odot$ & + & $\odot$ & $\odot$ & 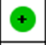 \\
\hline Jadzinsky 2009 & $\odot$ & $?$ & + & + & ○ & + & + \\
\hline NCT00316082 2009 & $?$ & $?$ & $\odot$ & + & $\odot$ & $\odot$ & $?$ \\
\hline NCT00839527 2014 & $?$ & $?$ & $\odot$ & + & $\odot$ & $\odot$ & $?$ \\
\hline NCT008490172014 & $?$ & $?$ & $\odot$ & $\odot$ & $\odot$ & $\odot$ & $?$ \\
\hline NCT01064687 2015 & $?$ & $?$ & $\odot$ & + & O & $\odot$ & $?$ \\
\hline NCT01117350 2014 & $?$ & $?$ & $\odot$ & $\odot$ & $\odot$ & $\odot$ & $?$ \\
\hline NCT01183013 2014 & $?$ & $?$ & $\odot$ & + & $\odot$ & $\odot$ & $?$ \\
\hline NCT012634962012 & $?$ & $?$ & $\odot$ & + & + & $\odot$ & $?$ \\
\hline NCT01519674 2014 & $?$ & $?$ & $\odot$ & + & $?$ & $\odot$ & $?$ \\
\hline Pfeffer 2015 & $\odot$ & $\odot$ & + & + & $\odot$ & $\odot$ & + \\
\hline Raz 2006 & $?$ & $?$ & $\odot$ & + & + & + & $?$ \\
\hline $\operatorname{Raz} 2008$ & $?$ & $?$ & $\odot$ & + & $\odot$ & $\odot$ & $?$ \\
\hline Scirica 2013 & $?$ & $?$ & $\odot$ & $\odot$ & $\odot$ & $\odot$ & $?$ \\
\hline White 2013 & $?$ & $?$ & $\odot$ & + & $\odot$ & $\odot$ & $?$ \\
\hline
\end{tabular}

4 Fig. 2 Risk of bias graph a reviewer's judgments about each risk of bias item presented as percentages across all included studies. b Risk of bias summary: reviewer's judgments about each risk of bias item in each study. (+) low risk of bias, (?) unclear, (-) high risk of bias

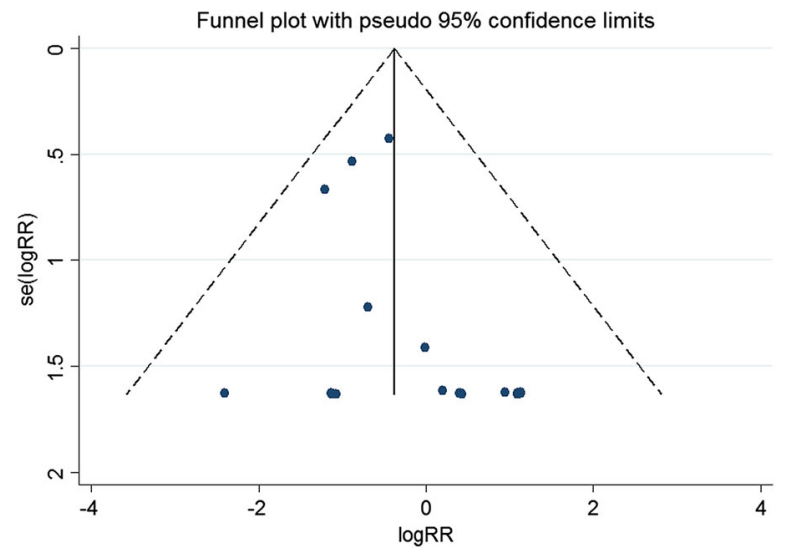

Fig. 3 Funnel plot analysis of 24 studies. Statistical analysis confirmed no evidence of publication bias. $R R$ relative risk

T2DM) and regimens of intervention groups (monotherapy or combination regimen). Hence, we further conducted subgroup analyses to investigate any more specific aspect (Fig. 4a, b).

Fig. 4 Forest plot of incretin-based therapy vs. placebo/ NIADs on pancreatic cancer risks. A fixed-effect model was used. No heterogeneity was shown among the studies (I-squared $=0.0 \%, P=0.943$ ). There were no increased risks of pancreatic neoplasms associated with incretin-based treatment than control groups (pooled $\mathrm{RR}=0.7,95 \% \mathrm{CI}$ $0.47-1.05, P=0.083$ ), irrespective of different types of incretin drugs (GLP-1 receptor agonists: pooled $\mathrm{RR}=0.58,95 \%$ CI $0.26-1.33 . P=0.198$; DPP-4 inhibitors: pooled $\mathrm{RR}=0.74,95 \% \mathrm{CI} 0.46-1.18, P=0.210$ ). The triangles represent individual studies and the size of the triangle represents the weight given to each study in the meta-analysis. The diamond represents the combined results. NIDAs incretin-based anti-diabetic drugs, $R R$ relative risk, $C I$ confidence interval, GLP glucagon-like peptide, $D P P-4$ dipeptidyl peptidase-IV 
a

Study

ID

Arechavaleta (2011)

Arjona (2013)

Barnett (2012)

Chan (2008)

Charbonnel (2006)

Diamant (2014)

Gallwitz (2012)

Goldstein (2008)

Green (2015)

Henry (2013)

Jadzinsky (2009)

NCT00316082 (2009)

NCT00839527 (2014)

NCT00849017 (2014)

NCT01064687 (2015)

NCT01117350 (2014)

NCT01183013 (2014)

NCT01263496 (2012)

NCT01519674 (2014)

Pfeffer (2015)

$\operatorname{Raz}(2006)$

$\operatorname{Raz}(2008)$

Scirica (2013)

White (2013)

Overall (I-squared $=0.0 \%, p=0.943$ )
Weight

$3.01(0.12,73.76) \quad 0.90$

$3.03(0.12,73.92) \quad 0.89$

$1.50(0.06,36.48) \quad 1.20$

$1.23(0.05,29.19) \quad 1.27$

$1.54(0.06,37.55) \quad 1.19$

$2.97(0.12,72.67) \quad 0.90$

$0.50(0.05,5.50) \quad 3.59$

$0.32(0.01,7.86) \quad 2.74$

$0.64(0.28,1.49) \quad 25.13$

$3.03(0.12,73.90) \quad 0.89$

$0.33(0.01,7.98) \quad 2.72$

$3.13(0.13,75.46) \quad 0.88$

$0.34(0.01,8.33) \quad 2.67$

$3.06(0.13,74.23) \quad 0.89$

$1.52(0.06,37.11) \quad 1.19$

$0.99(0.06,15.84) \quad 1.80$

$3.12(0.13,75.83) \quad 0.88$

$2.57(0.11,62.29) \quad 0.97$

$2.98(0.12,72.81) \quad 0.90$

$0.30(0.08,1.10) \quad 17.07$

$0.09(0.00,2.19) \quad 4.25$

$0.33(0.01,7.91) \quad 2.72$

$0.41(0.15,1.17) \quad 21.64$

$0.33(0.01,8.11) \quad 2.71$

$0.70(0.47,1.05) \quad 100.00$

271

b

Study
ID

$\mathrm{RR}(95 \% \mathrm{Cl})$

$\%$

DPP-4 Inhibitors

Arechavaleta (2011)

Barnett (2012)

Chan (2008)

Charbonnel (2006)

Gallwitz (2012)

Goldstein (2008)

Green (2015)

Henry (2013)

NCT00316082 (2009)

NCT00849017 (2014)

NCT01183013 (2014)

NCT01263496 (2012)

NCT01519674 (2014)

$\operatorname{Raz}$ (2006)

$\operatorname{Raz}(2008)$

Scirica (2013)

White (2013)

Subtotal (I-squared $=0.0 \%, p=0.893$ )

GLP-1 Receptor Agonists

Arjona (2013)

Diamant (2014)

Jadzinsky (2009)

NCT00839527 (2014)

NCT01064687 (2015)

NCT01117350 (2014)

Pfeffer (2015)

Subtotal (I-squared $=0.0 \%, p=0.709$ )

Overall (I-squared $=0.0 \%, p=0.943$ )

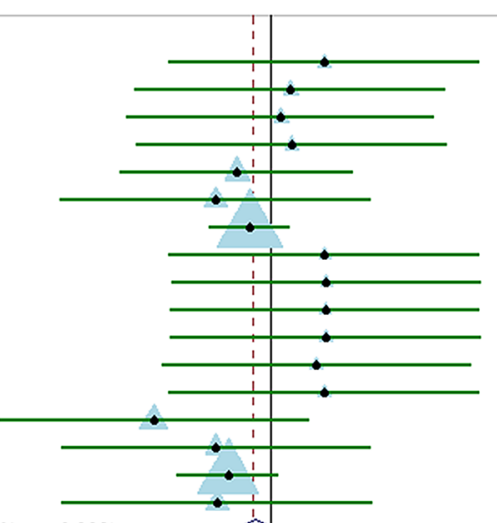

$3.01(0.12,73.76)$

$1.50(0.06,36.48) \quad 1.20$

$1.23(0.05,29.19) \quad 1.27$

$1.54(0.06,37.55) \quad 1.19$

$0.50(0.05,5.50) \quad 3.59$

$0.32(0.01,7.86) \quad 2.74$

$0.64(0.28,1.49) \quad 25.13$

$3.03(0.12,73.90) \quad 0.89$

$3.13(0.13,75.46) \quad 0.88$

$3.06(0.13,74.23) \quad 0.89$

$3.12(0.13,75.83) \quad 0.88$

$2.57(0.11,62.29) \quad 0.97$

$2.98(0.12,72.81) \quad 0.90$

$0.09(0.00,2.19) \quad 4.25$

$0.33(0.01,7.91) \quad 2.72$

$0.41(0.15,1.17) \quad 21.64$

$0.33(0.01,8.11) \quad 2.71$

$0.74(0.46,1.18) \quad 72.75$

$3.03(0.12,73.92) \quad 0.89$

$2.97(0.12,72.67) \quad 0.90$

$0.33(0.01,7.98) \quad 2.72$

$0.34(0.01,8.33) \quad 2.67$

$1.52(0.06,37.11) \quad 1.19$

$0.99(0.06,15.84) \quad 1.80$

$0.30(0.08,1.10) \quad 17.07$

$0.58(0.26,1.33) \quad 27.25$

$0.70(0.47,1.05) \quad 100.00$ 


\section{Effect of Study Duration}

The duration of the studies varied from 24 weeks to 5 years [22, 23]. In studies with duration longer than 104 weeks, the incidence of pancreatic neoplasm with incretin-based groups was lower than with placebo or non-incretin anti-diabetic regimens (pooled $\mathrm{RR}=0.50,95 \%$ CI $0.29-0.87, P=0.014$ ). There is no significant difference in risk of pancreatic cancer among trials less than 52 weeks (pooled $\mathrm{RR}=1.26,95 \%$ CI $0.54-2.98, P=0.593)$ and those of 52-104 weeks duration (pooled $\mathrm{RR}=0.93, \quad 95 \% \quad$ CI $\quad 0.37-2.34, \quad P=0.879)$ (Fig. 5a).

\section{Incretin-Based Therapy Versus Placebo or Other Anti-diabetic Drugs}

There are also differences among control groups within the included 24 studies. Seven trials applied incretin-matched placebo as parallel arms while 17 had non-incretin anti-diabetic drugs for control. Our results indicated decreased risk of pancreatic cancer within groups controlled by incretin-matched placebos (pooled $\mathrm{RR}=0.55,95 \%$ CI 0.32-0.93, $P=0.025)$. On the other hand, there was no increase in risk of pancreatic cancer as compared to the non-incretin anti-diabetic therapy (pooled $\mathrm{RR}=1.04,95 \%$ CI 0.54-2.01, $P=0.902)$ (Fig. 5b).

\section{Incretin-Based Monotherapy Versus Combination Regimen}

Within 24 trials, 14 studies $[15,17,19-22,24,25,27,28]$ had incretin-based combination regimen as one of the treatment arms (pooled RR $=0.92,95 \% \mathrm{CI}$ 0.45-1.90, $P=0.828$ ). The remaining ten studies had evaluated incretin-based
Fig. 5 Forest plot of subgroup analysis. a trial duration: within study groups in which trial duration exceeded 104 weeks, there was lower incidence of pancreatic neoplasms in incretin-based groups than those in placebo or NIADs ones (pooled RR $=0.50,95 \%$ CI $0.29-0.87$, $P=0.014)$. No significant difference was detected in risks of pancreatic cancer among trials less than 52 weeks (pooled RR $=1.26,95 \%$ CI $0.54-2.98, P=0.593$ ) and those with trial duration range from 52 to 104 weeks (pooled RR $=0.93,95 \%$ CI $0.37-2.34, P=0.879$ ). $N I D A s$ incretin-based anti-diabetic drugs, $R R$ relative risk, $C I$ confidence interval. b Incretin-based medication versus placebo or other anti-diabetic drugs: decreased risks of pancreatic cancer were identified in intervention studies controlled with incretin-matched placebos than those setting non-incretin-based anti-diabetic drugs as control (pooled RR $=0.55,95 \%$ CI $0.32-0.93, P=0.025$ ). $R R$ relative risk, $C I$ confidence interval. c Incretin-based monotherapy versus combination regimen: incretin mimetics used as either monotherapy (pooled $\mathrm{RR}=0.62,95 \%$ CI $0.38-1.01, P=0.055)$ or combination regimen (pooled $\mathrm{RR}=0.92,95 \%$ CI $0.45-1.90$, $P=0.828)$ did not increase risks of pancreatic cancer than non-incretin-based anti-diabetic drugs (NIADs) or placebos. $R R$ relative risk, $C I$ confidence interval, NIDAs incretin-based anti-diabetic drugs. $\mathbf{d}$ Pancreatic cancer as principal outcome or not: studies that considered the incidence of pancreatic cancer to be one of the principal outcome variables did not show an increased risk of pancreatic cancer (pooled $\mathrm{RR}=1.17,95 \%$ CI $0.62-2.19, P=0.630$ ), whereas studies reporting pancreatic cancer events as non-principal outcome (pooled $\mathrm{RR}=0.48,95 \%$ CI $0.28-0.84, P=0.010) . R R$ relative risk, $C I$ confidence interval

monotherapy $\quad$ (pooled $\quad \mathrm{RR}=0.62, \quad 95 \% \quad \mathrm{CI}$ $0.38-1.01, \quad P=0.055)$. The pooled results indicate that both types of regimens did not increase risk of pancreatic cancer with regards to incretin treatment (Fig. 5c).

\section{Pancreatic Cancer as Principal Outcome or Not}

Nineteen studies considered the incidence of pancreatic cancer to be one of the principal outcome variables (pooled $\mathrm{RR}=1.17,95 \% \mathrm{CI}$ $0.62-2.19, P=0.630)$. The remaining five studies investigated pancreatic cancer events 
a

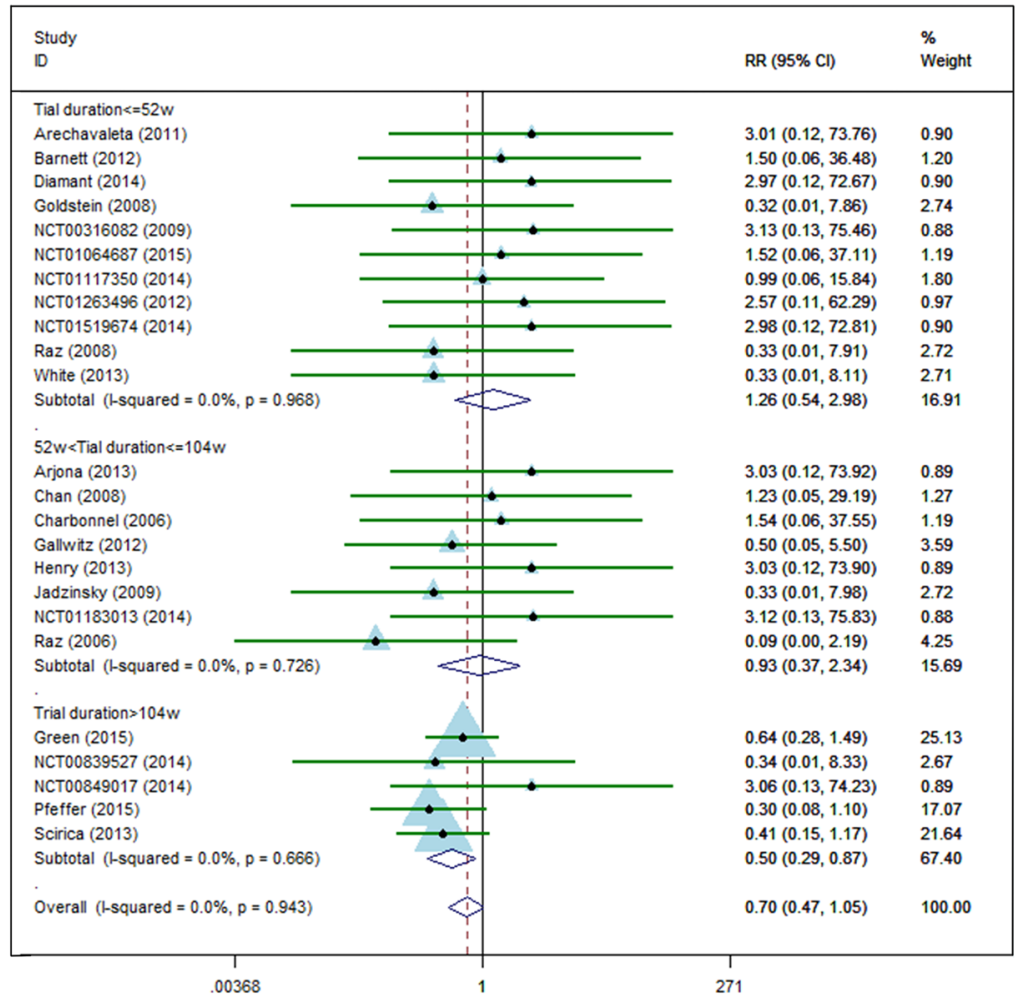

b

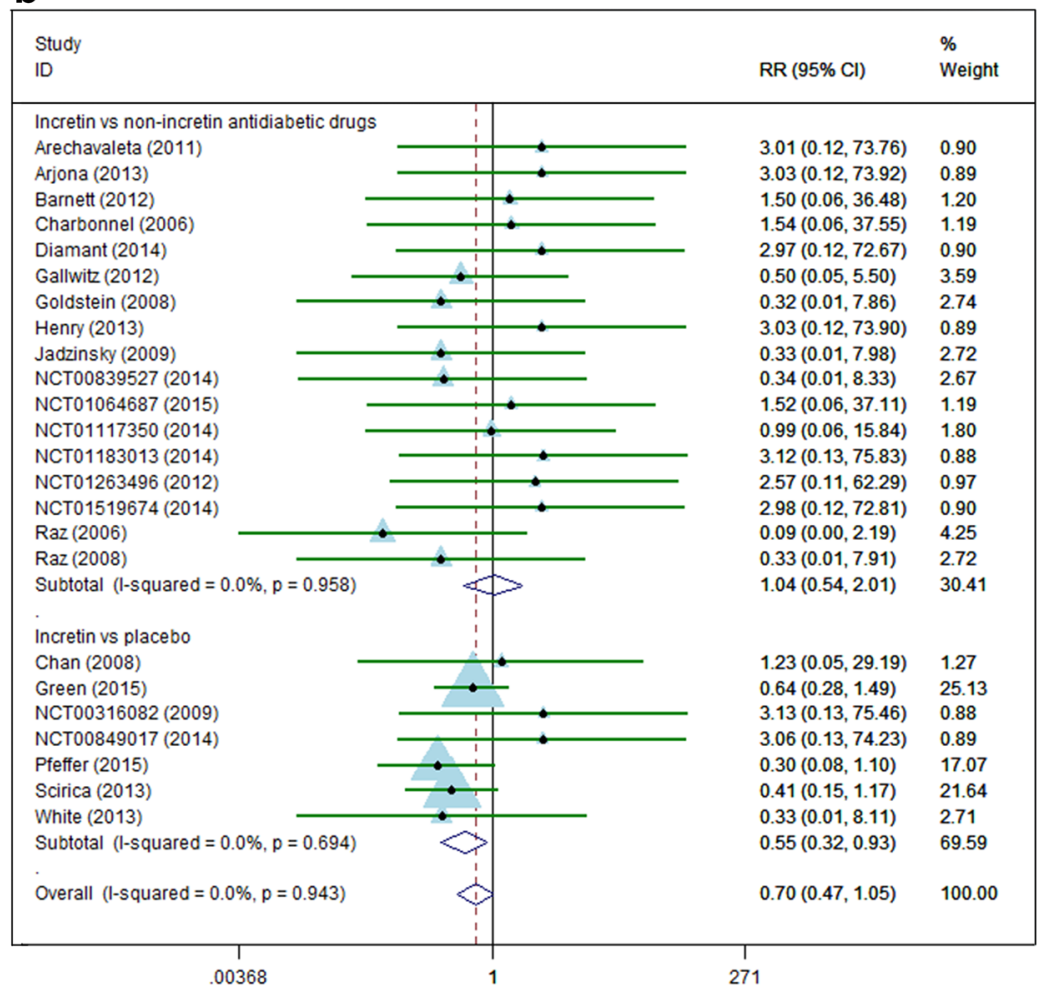


C

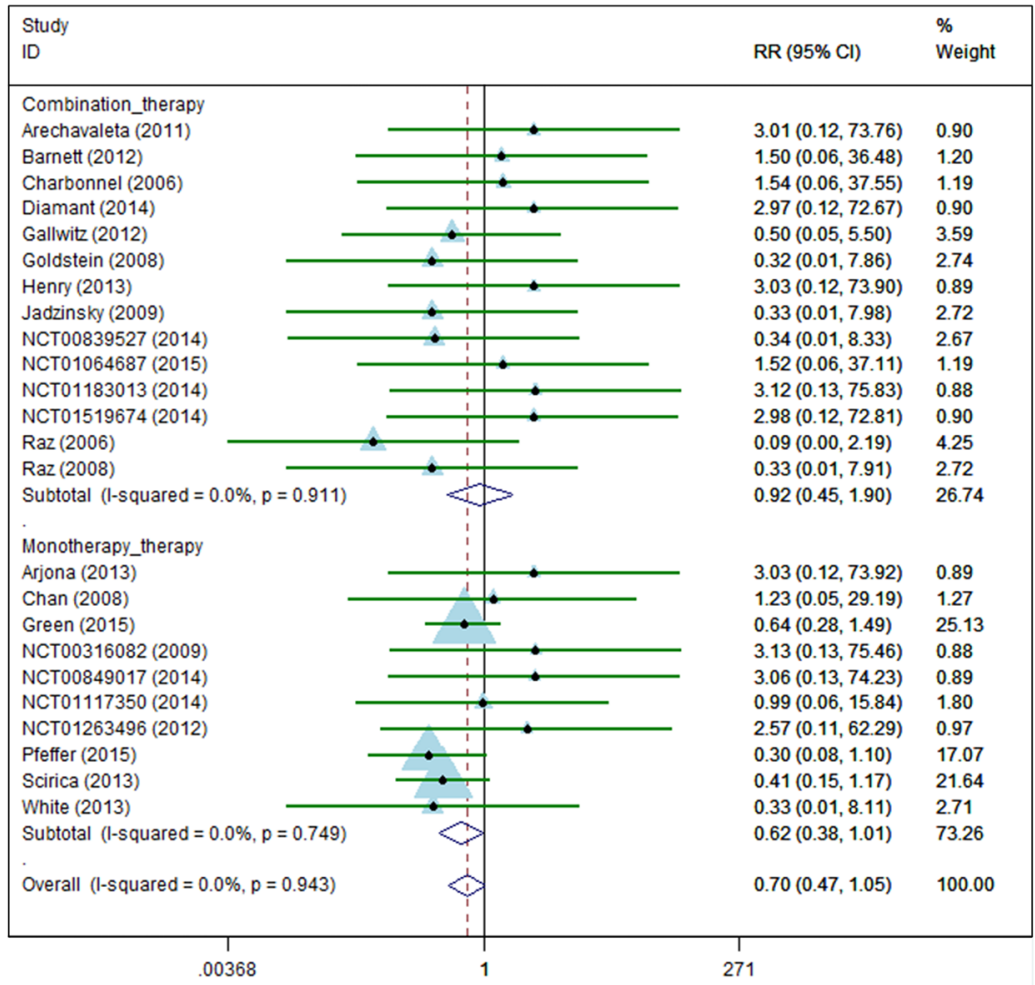

d

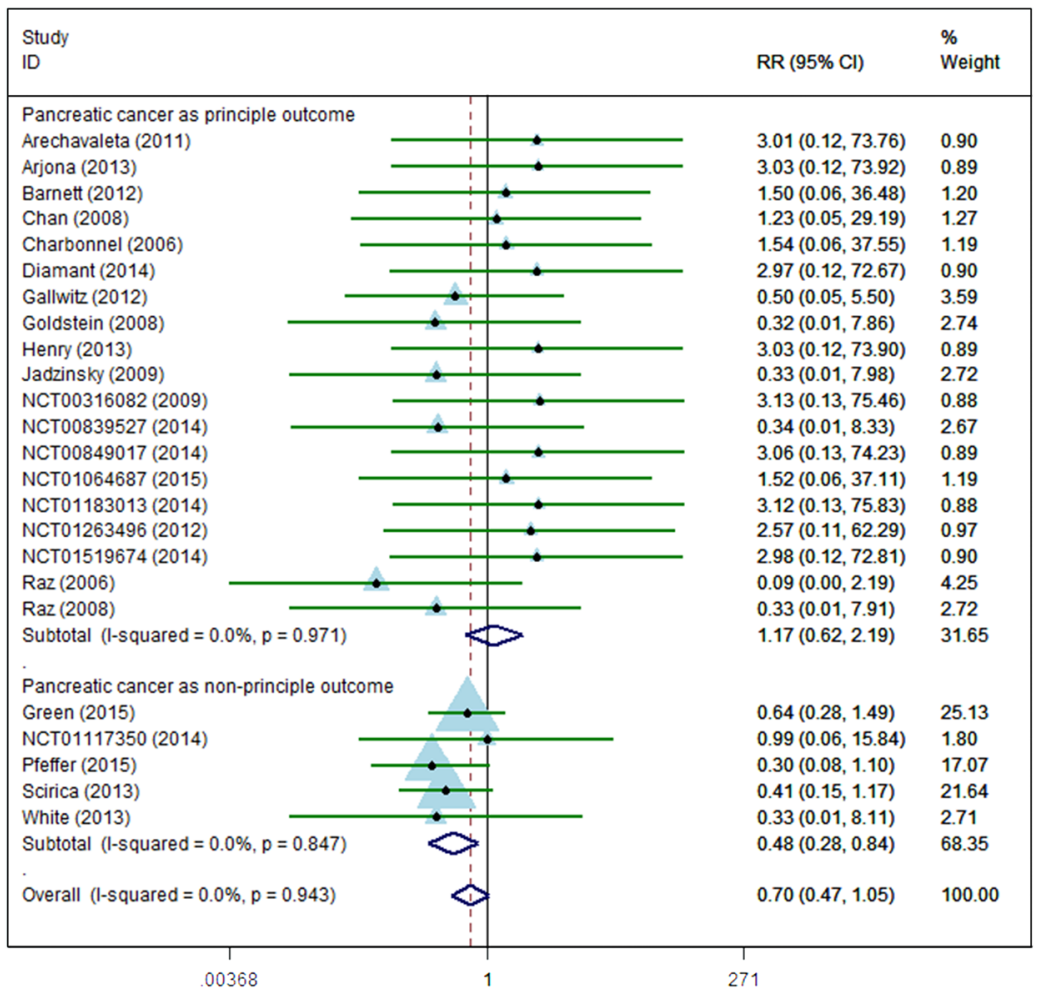

Fig. 5 continued 
as non-principal outcome (pooled $\mathrm{RR}=0.48$, 95\% CI 0.28-0.84, $P=0.010$ ) (Fig. 5d).

\section{DISCUSSION}

Our meta-analysis shows that: (1) overall, there is no evidence to indicate increased risk of pancreatic cancer associated with incretin-based treatment in patients with T2DM; (2) there was lower incidence of pancreatic neoplasm in incretin-based groups than those in placebo or non-incretin-based anti-diabetic drugs in studies with study period longer than 104 weeks; (3) also, decreased risk of pancreatic cancer was identified among intervention studies controlled by incretin-matched placebos than those paralleled with non-incretin-based anti-diabetic drugs; (4) incretin-based drugs used as either monotherapy or combination regimen did not increase risk of pancreatic cancer as compared to non-incretin-based anti-diabetic drugs or placebo.

At present, several meta-analyses have been carried out with regards to the safety of incretin-based therapy [35-49]. It is reported that incretin-based drugs are associated with increased risk of cardiovascular events, acute pancreatitis and several types of neoplasm [35-49]. However, some meta-analyses had only focused on evaluation of a single drug classified within the incretin drug category [36, 38, 39, 45, 48]. As for pancreatic safety, most of the meta-analyses have just provided combined data of the risk of acute pancreatitis with incretin therapies [39-43, 49]. Few meta-analysis specially investigated the association regarding the incidence of pancreatic cancer. Although one meta-analysis [39] investigated such association, it only included two single drugs (exenatide and liraglutide). Here, we tried to comprehensively analyze all the incretin-related drugs together for the first time, including both GLP-1RAs and DPP-IV inhibitors.

The overall results indicated in our study were consistent with the latest FDA and EMA database assessment of pancreatic safety [13]. Irrespective of different types of incretin-based drugs, there was no evidence of increased risk of pancreatic neoplasm associated with incretin-based treatment. This result is consistent with human and animal studies performed by the pharmaceutical companies $[36,50]$.

Although several observational studies have shown an increased risk of pancreatic cancer with incretin-based drugs, these data need to be reevaluated due to the potential mechanistic questions [51, 52]. Some adjusting methods had been applied in order to reduce the confounding factors, but it is still difficult to measure such large data by a reliable methodology on the estimated population $[8,9$, 53-60]. Additionally, the association between diabetes mellitus itself and pancreatic cancer is also very complicated as the long-duration of T2DM is considered a risk factor for pancreatic cancer [53, 54]. Therefore, the results of observational studies need to be interpreted with caution.

As for RCTs, due to the relatively restrained and stringent inclusion criteria, potential selection bias might have existed for the enrolled patients, thus reducing the risk of pancreatic cancer [41]. Therefore, disparities between observational studies and RCTs can be ascribed to individual variations. Thus, more large-scale surveillance of both epidemiological and RCTs is needed urgently for further evaluation.

According to the current guidelines, incretin-based therapies are recommended for use as monotherapy or in combination with 
other anti-diabetic agents such as metformin [61]. In our study, we did not find any increased risk of pancreatic cancer with incretin-based therapies as compared to control.

Duration of the study is possibly the second influential factor for risk of pancreatic cancer. Here, we applied two cut-out points (52 and 104 weeks) to classify the studies into three categories. Surprisingly, we detected a lower incidence of pancreatic neoplasm among those with drug intake for more than 104 weeks in incretin-based groups than those in placebo or non-incretin-based anti-diabetic therapy. This result is probably due to four high-quality large RCTs $[23,26,29,30]$. They all applied more than 2 years follow-up periods and concluded that pancreatic cancer was uncommon and occurred more often in the placebo group, but this difference was not significant in each trial. A recently reported international multicentre cohort study showed the same results. They reported that duration of more than 2 years of incretin use generated pooled hazard ratio close to or below unity $(0.62,0.36$ to 1.07$)[9,58]$, suggesting lower risk of pancreatic cancer. Although incretin drugs may cause a non-physiological condition by promoting effective beta-cells and suppressing alpha cells, the long-term regular use may promotes a new balance of pancreatic secretion and reduces the possible side effects on exocrine pancreas. However, the longest trial in our study had a 6-year study period, but it may take up to 12 years for initiated pancreatic intraepithelial lesions to develop a parental clone which initiates infiltrating pancreatic carcinomas [62]. Thus, the current RCTs were still not long enough to detect a causal effect of incretin mimetics on pancreatic cancer. Long-term surveillance ( $>10$ years) of neoplasm on the exocrine pancreas is required in the future studies of incretin-based therapy.
In our study, the total incidence of pancreatic cancers was very low (1.59\%), resulting in the widening of $95 \%$ CIs. This may indicate the possibility of underestimated events. Actually, in all 24 included studies, most of them were phase III trials, thus these might have been designed for evaluating the pharmacological efficacy of drugs rather than safety concerns. Consequently, some adverse events possibly remain unreported. Additionally, we found decreased risk of pancreatic cancer within intervention groups controlled by incretin-matched placebos compared to those using non-incretin-based anti-diabetic drugs such as insulin, sulfonylureas, thiazolidinediones and sodium glucose cotransporter-2 inhibitors. Within the seven trials with incretin-matched placebos, four were recent large RCTs including SAVOR-TIMI 53 trial (NCT00790205) and EXAMINE trial (NCT00968708) [23, 26, 29, 30, 63]. Given the long-term follow-up surveillance and large-scale of population, the pooled results may be more convincing. However, these four studies had mainly focused on investigating cardiovascular events associated with incretin-based drugs $[23,26,29,30]$. Hence, we could not exclude the possibility of selection bias and pancreatic cancer events going unreported.

\section{Strengths and Limitations}

Our meta-analysis has several strengthens. This is the first comprehensive meta-analysis to assess all types of incretin-based therapies. Specific types of GLP-1 receptors (albiglutide, exenatide, liraglutide) and DPP-IV inhibitors (alogliptin, saxagliptin, sitagliptin, linagliptin) approved by both FDA and EMA were included. We also used the ClinicalTrials.gov search engine as one important resource of RCTs. In 
addition, we conducted several subgroup analyses in order to reduce potential heterogeneity among different RCTs. Furthermore, we identified eight observational studies investigating the relationship of pancreatic cancer and incretin-based therapy [53-60], however, we finally included RCTs only as some of these observational studies have inherent bias and confounding by indication and should not be added to trials that are internally randomized. In addition, there are no specific diagnostic criteria of pancreatic cancer among all eligible RCTs, which should also be a limitation in our study. It is reported that the risk of pancreatic cancer includes both adenocarcinoma and neuroendocrine tumors [64-65], but we were unable to analyze the incidence of both types due to limited information of tumor classification provided by RCTs.

\section{CONCLUSION}

This meta-analysis provides reassuring evidence against the hypothesis that incretin-based therapies increase the risk of pancreatic cancer. Further, subgroup analyses suggest possible beneficial effects which require direct testing in trials designed a priori to do so. Given the potential carcinogenic potency, more large-scale RCTs with longstanding surveillance of pancreatic safety are urgently warranted, whereas epidemiological studies will also continue to be needed for long-term surveillance if such RCTs are absent.

\section{ACKNOWLEDGMENTS}

No funding or sponsorship was received for this study or publication of this article.
This study was supported by grants from the National Natural Science Foundation of China (Nos. 81270476 and 81470830).

All named authors meet the International Committee of Medical Journal Editors (ICMJE) criteria for authorship for this manuscript, take responsibility for the integrity of the work as a whole, and have given final approval for the version to be published.

We thank Dr. Hongwen Zhou (Department of Endocrinology, The First Affiliated Hospital of Nanjing Medical University, Nanjing, China), Dr Zhenyu Zhang (Nanjing First Hospital, Nanjing Medical University, Nanjing 210006, China), Dr Lin Lin and Dr Hongjie Zhang (The First Affiliated Hospital of Nanjing Medical University, Nanjing, China) for providing access to the data of clinical trial for all chemopreventive agents reviewed in this article.

Han Chen conceptualized and designed the study, acquired the data and wrote the first draft; Xiaoying Zhou performed the statistical analysis and revised the manuscript for important intellectual content; Bingtuan Liu, Tao Chen, Wujuan Jin, Huiyuan $\mathrm{Gu}$ and Tianyuan Hong acquired the data and revised the manuscript for important intellectual content; Guoxin Zhang designed the study and revised the manuscript for important intellectual content.

Disclosures. Han Chen, Xiaoying Zhou, Tao Chen, Bingtuan Liu, Wujuan Jin, Huiyuan Gu, Tianyuan Hong and Guoxin Zhang have nothing to disclose.

Compliance with Ethics Guidelines. This article is based on previously conducted studies and does not involve any new studies of human or animal subjects performed by any of the authors. 
Open Access. This article is distributed under the terms of the Creative Commons Attribution-NonCommercial 4.0 International License (http://creativecommons.org/licenses/ by-nc/4.0/), which permits any noncommercial use, distribution, and reproduction in any medium, provided you give appropriate credit to the original author(s) and the source, provide a link to the Creative Commons license, and indicate if changes were made.

\section{REFERENCES}

1. Drucker DJ, Nauck MA. The incretin system: glucagon-like peptide-1 receptor agonists and dipeptidyl peptidase- 4 inhibitors in type 2 diabetes. Lancet. 2006;368:1696-705.

2. Ismail-Beigi F. Glycemic management of type 2 diabetes mellitus. N Engl J Med. 2012;366:1319-27.

3. Cefalu WT, Buse JB, Del Prato S, et al. Beyond Metformin: safety considerations in the decision-making process for selecting a second medication for type 2 diabetes management. Diabetes Care. 2014;37(9):2647.

4. Drucker DJ. The biology of incretin hormones. Cell Metab. 2006;3:153-65.

5. Inzucchi SE, Bergenstal RM, Buse JB, et al. Management of hyperglycemia in type 2 diabetes: a patient-centered approach. Position Statement of the American Diabetes Association (ADA) and the European Association for the Study of Diabetes (EASD). Diabetes Care. 2012;35:1364-79.

6. Karagiannis T, Paschos P, Paletas K, et al. Dipeptidyl peptidase- 4 inhibitors for treatment of type 2 diabetes mellitus in the clinical setting: systematic review and meta-analysis. BMJ. 2012;344:e1369.

7. Deacon CF, Mannucci E, Ahr'en B. Glycaemic efficacy of glucagon-like peptide-1 receptor agonists and dipeptidyl peptidase- 4 inhibitors as add-on therapy to metformin in subjects with type 2 diabetes-a review and meta analysis. Diabetes Obes Metab. 2012;14:762-7.

8. Elashoff M, Matveyenko AV, Gier B, et al. Pancreatitis, pancreatic, and thyroid cancer with glucagon-like peptide-1-based therapies. Gastroenterology. 2011;141:150-6.
9. Spranger J, Gundert-Remy U, Stammschulte T. GLP-1-based therapies: the dilemma of uncertainty. Gastroenterology. 2011;141:20-3.

10. Egan AG, Blind E, Dunder K, et al. Pancreatic safety of incretin-based drugs-FDA and EMA assessment. N Engl J Med. 2014;370(9):794-7.

11. Butler PC, Elashoff M, Elashoff R, et al. A critical analysis of the clinical use of incretin-based therapies: are the GLP-1 therapies safe? Diabetes Care. 2013;36:2118-25.

12. Veld P, De In't Munck N, Van Belle K, et al. Beta-cell replication is increased in donor organs from young patients after prolonged life support. Diabetes. 2010;59:1702-8.

13. Forsmark CE. Incretins, diabetes, pancreatitis and pancreatic cancer: what the GI specialist needs to know. Pancreatology. 2016;16(1):10-3.

14. From National Library of Medicine (US). 2000. http://clinicaltrials.gov/.

15. Arechavaleta R, Seck T, Chen Y, et al. Efficacy and safety of treatment with sitagliptin or glimepiride in patients with type 2 diabetes inadequately controlled on metformin monotherapy: a randomized, double-blind, non-inferiority trial. Diabetes Obes Metab. 2011;13(2):160-8.

16. Arjona Ferreira JC, Marre M, Barzilai N, et al. Efficacy and safety of sitagliptin versus glipizide in patients with type 2 diabetes and moderate-to-severe chronic renal insufficiency. Diabetes Care. 2013;36(5):1067-73.

17. Barnett AH, Charbonnel B, Donovan M, et al. Effect of saxagliptin as add-on therapy in patients with poorly controlled type 2 diabetes on insulin alone or insulin combined with metformin. Curr Med Res Opin. 2012;28(4):513-23.

18. Chan JC, Scott R, Arjona Ferreira JC, et al. Safety and efficacy of sitagliptin in patients with type 2 diabetes and chronic renal insufficiency. Diabetes Obes Metab. 2008;10(7):545-55.

19. Charbonnel B, Karasik A, Liu J, Sitagliptin Study 020 Group, et al. Efficacy and safety of the dipeptidyl peptidase-4 inhibitor sitagliptin added to ongoing metformin therapy in patients with type 2 diabetes inadequately controlled with metformin alone. Diabetes Care. 2006;29(12):2638-43.

20. Diamant M, Nauck MA, Shaginian R, et al. Glucagon-like peptide 1 receptor agonist or bolus insulin with optimized basal insulin in type 2 diabetes. Diabetes Care. 2014;37(10):2763-73. 
21. Gallwitz B, Rosenstock J, Rauch T, et al. 2-year efficacy and safety of linagliptin compared with glimepiride in patients with type 2 diabetes inadequately controlled on metformin: a randomised, double-blind, non-inferiority trial. Lancet. 2012;380(9840):475-83.

22. Goldstein BJ, Feinglos MN, Lunceford JK, et al. Effect of initial combination therapy with sitagliptin, a dipeptidyl peptidase-4 inhibitor, and metformin on glycemic control in patients with type 2 diabetes. Diabetes Care. 2007;30(8):1979-87.

23. Green JB, Bethel MA, Armstrong PW, TECOS Study Group, et al. Effect of sitagliptin on cardiovascular outcomes in type 2 diabetes. $\mathrm{N}$ Engl J Med. 2015;373:232-42.

24. Henry RR, Staels B, Fonseca VA, et al. Efficacy and safety of initial combination treatment with sitagliptin and pioglitazone-a factorial study. Diabetes Obes Metab. 2014;16(3):223-30.

25. Jadzinsky $M$, Pfützner A, Paz-Pacheco E, et al. Saxagliptin given in combination with metformin as initial therapy improves glycaemic control in patients with type 2 diabetes compared with either monotherapy: a randomized controlled trial. Diabetes Obes Metab. 2009;11(6):611-22.

26. Pfeffer MA, Claggett B, Diaz R, ELIXA Investigators, et al. Lixisenatide in patients with type 2 diabetes and acute coronary syndrome. $\mathrm{N}$ Engl J Med. 2015;373:2247-57.

27. Raz I, Hanefeld M, Xu L, et al. Efficacy and safety of the dipeptidyl peptidase- 4 inhibitor sitagliptin as monotherapy in patients with type 2 diabetes mellitus. Diabetologia. 2006;49(11):2564-71.

28. Raz I, Chen Y, Wu M, et al. Efficacy and safety of sitagliptin added to ongoing metformin therapy in patients with type 2 diabetes. Curr Med Res Opin. 2008;24(2):537-50.

29. Scirica BM, Bhatt DL, Braunwald E, SAVOR-TIMI 53 Steering Committee and Investigators, et al. Saxagliptin and cardiovascular outcomes in patients with type 2 diabetes mellitus. $\mathrm{N}$ Engl J Med. 2013;369:1317-26.

30. White WB, Cannon CP, Heller SR, EXAMINE Investigators, et al. Alogliptin after acute coronary syndrome in patients with type 2 diabetes. N Engl J Med. 2013;369:1327-35.

31. Begg CB, Mazumdar M. Operating characteristics of a rank correlation test for publication bias. Biometrics. 1994;50:1088-101.
32. Egger M, Smith GD, Schneider M, Minder C. Bias in meta-analysis detected by a simple, graphical test. BMJ. 1997;315:629-34.

33. The Cochrane Collaboration. Cochrane handbook for systematic reviews of interventions (Version 5.1.0). March, 2011. http://handbook.cochrane. org. Accessed 20 Oct 2015.

34. Higgins JP, Thompson SG, Deeks JJ, Altman DG. Measuring inconsistency in meta-analysis. BMJ. 2003;327:557-60.

35. Amori RE, Lau J, Pittas AG, et al. Efficacy and safety of incretin therapy in type 2 diabetes: systematic review and meta-analysis. JAMA. 2007;298(2):194-206.

36. Engel SS, Round E, Golm GT, et al. Safety and tolerability of sitagliptin in type 2 diabetes: pooled analysis of 25 clinical studies. Diabetes Ther. 2013;4(1):119-45.

37. Fakhoury WK, Lereun C, Wright D, et al. A meta-analysis of placebo-controlled clinical trials assessing the efficacy and safety of incretin-based medications in patients with type 2 diabetes. Pharmacology. 2010;86(1):44-57.

38. Lehrke M, Marx N, Patel S, et al. Safety and tolerability of linagliptin in patients with type 2 diabetes: a comprehensive pooled analysis of 22 placebo-controlled studies. Clin Ther. 2014;36(8):1130-46.

39. Alves C, Batel-Marques F, Macedo AF, et al. A meta-analysis of serious adverse events reported with exenatide and liraglutide: acute pancreatitis and cancer. Diabetes Res Clin Pract. 2012;98(2):271-84.

40. Li L, Shen J, Bala MM, et al. Incretin treatment and risk of pancreatitis in patients with type 2 diabetes mellitus: systematic review and meta-analysis of randomised and non-randomised studies. BMJ. 2014;348:g2366.

41. Monami M, Dicembrini I, Mannucci E, et al. Dipeptidyl peptidase-4 inhibitors and pancreatitis risk: a meta-analysis of randomized clinical trials. Diabetes Obes Metab. 2014;16(1):48-56.

42. Monami M, Dicembrini I, Martelli D, et al. Safety of dipeptidyl peptidase-4 inhibitors: a meta-analysis of randomized clinical trials. Curr Med Res Opin. 2011;27(Suppl 3):57-64.

43. Monami M, Dicembrini I, Nardini C, et al. Glucagon-like peptide-1 receptor agonists and pancreatitis: a meta-analysis of randomized 
clinical trials. Diabetes Res Clin Pract. 2014;103(2):269-75.

44. Peng H, Want LL, Aroda VR, et al. Safety and tolerability of glucagon-like peptide-1 receptor agonists utilizing data from the exenatide clinical trial development program. Curr Diab Rep. 2016;16(5):44.

45. Schernthaner G, Barnett AH, Emser A, et al. Safety and tolerability of linagliptin: a pooled analysis of data from randomized controlled trials in 3572 patients with type 2 diabetes mellitus. Diabetes Obes Metab. 2012;14(5):470-8.

46. Schernthaner G, Barnett AH, Patel S, et al. Safety and efficacy of the dipeptidyl peptidase- 4 inhibitor linagliptin in elderly patients with type 2 diabetes: a comprehensive analysis of data from 1331 individuals aged $\geq 65$ years. Diabetes Obes Metab. 2014;16(11):1078-86.

47. Shyangdan DS, Royle PL, Clar C, et al. Glucagon-like peptide analogues for type 2 diabetes mellitus: systematic review and meta-analysis. BMC Endocr Disord. 2010;10:20.

48. Singh-Franco D, Singh-Franco D, et al. The effect of linagliptin on glycaemic control and tolerability in patients with type 2 diabetes mellitus: a systematic review and meta-analysis. Diabetes Obes Metab. 2012;14(8):694-708.

49. Wang T, Wang F, Gou Z, et al. Using real-world data to evaluate the association of incretin-based therapies with risk of acute pancreatitis: a meta-analysis of $1,324,515$ patients from observational studies. Diabetes Obes Metab. 2015;17(1):32-41.

50. Busch SJ, Hoffmann P, Sahota P, Johnson R, Kothny W, Meyer F, et al. Studies in rodents with the dipeptidyl peptidase-4 inhibitor vildagliptin to evaluate possible drug-induced pancreatic histological changes that are predictive of pancreatitis and cancer development in man. Diabetes Obes Metab. 2013;15:72-6.

51. Engel SS, Round E, Golm GT, Kaufman KD, Goldstein BJ. Safety and tolerability of sitagliptin in type 2 diabetes: pooled analysis of 25 clinical studies. Diabetes Ther. 2013;4(1):119-45.

52. Bonner-Weir S, In't Veld PA, Weir GC. Reanalysis of study of pancreatic effects of incretin therapy: methodological deficiencies. Diabetes Obes Metab. 2014;16(7):661-6.

53. Pannala R, Basu A, Petersen GM, Chari ST. New-onset diabetes: a potential clue to the early diagnosis of pancreatic cancer. Lancet Oncol. 2009;10:88-95.
54. Ben $\mathrm{Q}, \mathrm{Xu} \mathrm{M}$, Ning $\mathrm{X}$, et al. Diabetes mellitus and risk of pancreatic cancer: a meta-analysis of cohort studies. Eur J Cancer. 2011;47:1928-37.

55. Tseng $\mathrm{CH}$. Sitagliptin and pancreatic cancer risk in patients with type 2 diabetes. Eur J Clin Invest. 2016;46(1):70-9.

56. Romley JA, Goldman DP, Solomon $\mathrm{M}$, et al. Exenatide therapy and the risk of pancreatitis and pancreatic cancer in a privately insured population. Diabetes Technol Ther. 2012;14(10):904-11.

57. Knapen LM, van Dalem J, Keulemans YC, et al. Use of incretin agents and risk of pancreatic cancer: a population-based cohort study. Diabetes Obes Metab. 2016;18(3):258-65.

58. Elashoff M, Matveyenko AV, Gier B, et al. Pancreatitis, pancreatic, and thyroid cancer with glucagon-like peptide-1-based therapies. Gastroenterology. 2011;141(1):150-6.

59. Azoulay L, Filion KB, Platt RW, et al. Incretin based drugs and the risk of pancreatic cancer: international multicentre cohort study. BMJ. 2016;352:i581.

60. Gokhale M, Buse JB, Gray CL, et al. Dipeptidyl-peptidase-4 inhibitors and pancreatic cancer: a cohort study. Diabetes Obes Metab. 2014;16(12):1247-56.

61. Rodbard HW, Jellinger PS, Davidson JA, et al. Statement by an American Association of Clinical Endocrinologists/American College of Endocrinology consensus panel on type 2 diabetes mellitus: an algorithm for glycemic control. Endocr Pract. 2009; 15:540-59.

62. Yachida S, Jones S, Bozic I, et al. Distant metastasis occurs late during the genetic evolution of pancreatic cancer. Nature. 2010;467:1114-7.

63. Raz I, Bhatt DL, Hirshberg B. Incidence of pancreatitis and pancreatic cancer in a randomized controlled multicenter trial (SAVOR-TIMI 53) of the dipeptidyl peptidase-4 inhibitor saxagliptin. Diabetes Care. 2014;37(9):2435-41.

64. Butler AE, Campbell-Thompson M, Gurlo T, Dawson DW, Atkinson M, Butler PC. Marked expansion of exocrine and endocrine pancreas with incretin therapy in humans with increased exocrine pancreas dysplasia and the potential for glucagon-producing neuroendocrine tumors. Diabetes. 2013;62:2595-604.

65. Halfdanarson TR, Pannala R. Incretins and risk of neoplasia. BMJ. 2013;346:f3750. 